\title{
Effect of Young's modulus evolution on residual stress measurement of thermal barrier coatings by $\mathrm{X}$-ray diffraction
}

\author{
Q. Chen ${ }^{(a, b)}$, W. G. Mao ${ }^{(a, b) *}$, Y. C. Zhou ${ }^{(a, b)}, \quad$ C. $\operatorname{Lu}^{(\mathrm{c})}$ \\ (a) Faculty of Materials, Optoelectronics and Physics, Xiangtan University, Hunan 411105, China \\ (b) Key Laboratory of Low Dimensional Materials \& Application Technology, Ministry of Education, \\ Xiangtan University, Hunan 411105, China \\ ${ }^{(c)}$ Department of Mechanical Engineering, Curtin University of Technology, Western Australia 6845, \\ Australia
}

\begin{abstract}
Subjected to thermal cycling, the apparent Young's modulus of air plasma-sprayed (APS) 8 wt.\% $\mathrm{Y}_{2} \mathrm{O}_{3}$ stabilized $\mathrm{ZrO}_{2}$ (8YSZ) thermal barrier coatings (TBCs) was measured by nanoindentation. Owing to the effects of sintering and porous microstructure, the apparent Young's modulus follows a Weibull distribution and changes from 50 to $93 \mathrm{GPa}$ with an increase of thermal cycling. The evolution of residual stresses in the top coating of an 8YSZ TBC system was determined by X-ray diffraction (XRD). The residual stresses derived from the XRD data are well consistent with that obtained by the Vickers indention. It is shown that the evolution of Young's modulus plays an important role in improving the measurement precision of residual stresses in TBCs by XRD.
\end{abstract}

Keywords: thermal barrier coatings; X-ray diffraction; residual stress; Young's modulus

\footnotetext{
${ }^{*}$ Corresponding author: W. G. Mao, Faculty of Materials, Optoelectronics and Physics, Xiangtan University, Hunan 411105, China. Tel: +86-731-58298580, E-mail: ssamao@xtu.edu.cn.
} 


\section{Introduction}

Thermal barrier coatings (TBCs) with NiCrAlY bond coat and 8 wt.\% $\mathrm{Y}_{2} \mathrm{O}_{3}$-stabilized $\mathrm{ZrO}_{2}$ (8YSZ) ceramic top coat have been widely used in aircraft engines and gas turbines to protect basic materials (e.g., advanced Ni-superalloys) against high temperature and oxidation, and thereby to increase the lifetime of components [1-3]. However, thermal or residual stresses in TBCs gradually accumulate in their applications due to the mismatch of material properties and high-temperature creep, which may directly cause adhesive failure (delamination at interface) or cohesive failure (spalling or micro-cracking within ceramic coating) [3-7]. Therefore, the thermal and residual stresses are one of the most important factors in predicting the performance and lifetime of a TBC system $[8,9]$. The X-Ray diffraction (XRD) technique has been widely applied to study the evolution of residual stress in 8YSZ TBCs under thermal cycling [10-13]. In general, residual stress can be calculated by a typical equation [14], in which Young's modulus and Poisson's ratio are usually supposed as constants, independent of the number of thermal cycling. However, in an air plasma-sprayed (APS) 8YSZ TBC system, the Young's modulus of top coating (8YSZ) may change with thermal cycles due to the effects of sintering and porous microstructure [15-17]. The evolution of Young's modulus would influence the accuracy of measurement of residual stress. In this paper, the apparent Young's modulus of 8 YSZ TBCs subjected to thermal cycling was measured by nanoindentation, and then in combination with the data from XRD, these results were used to calculate the residual stress of TBCs. Finally, the Vickers indentation was applied to verify the results obtained by XRD.

\section{Experimental}




\subsection{Specimen preparation}

A type of high-temperature Ni-superalloy (GH3030) was selected as substrate and its nominal chemical composition is $\mathrm{Ni}-22 \mathrm{Cr}-1 \mathrm{Fe}-0.1 \mathrm{Al}$ in weight percent. The NiCrAlY powder with grain sizes of $20-50 \mu \mathrm{m}$ was sprayed on a Ni-superalloy substrate of $200 \times 20 \times 2 \mathrm{~mm}$ with substrate temperature of $\sim 473 \mathrm{~K}$ by low pressure plasma spray technique. The 8 YSZ powder with grain sizes of 20-60 $\mu \mathrm{m}$ was deposited as the top coating. The thicknesses of bond and top coats are $100 \mu \mathrm{m}$ and $300 \mu \mathrm{m}$, respectively. In this work, the spraying equipment is composed of a Miller Thermal Torch SG100 and Praxair 7700 (Plasma Technik AG). The plasma spraying parameters are listed in Table 1. Before the deposition of YSZ, pre-treatment in vacuum and pre-oxidation in air were carried out at $1323 \mathrm{~K}$. After being sprayed, the massive specimens were cut into pieces of $15 \times 5 \times 2.4 \mathrm{~mm}^{3}$ by a commercial cutting machine (IsoMet巴 4000).

\subsection{Thermal cycling}

To simulate high-temperature exposure inside a turbine, the 8YSZ TBC specimens were subjected to thermal cycling in a high temperature furnace. Each thermal cycle consists of 10 minutes heating up to $1403 \mathrm{~K}, 40$ minutes holding, and 10 minutes forced-air-quenching. The total of 35 specimens (five specimens of each type) was tested, and the maximum number of thermal cycling was about 250. The residual stresses in all specimens after thermal cycling but before polishing were directly measured by XRD. These TBC specimens were slightly polished by using white alumina slurry with the grit sizes of 15,10 and $2.5 \mu \mathrm{m}$, and then chemical mechanical polishing by a polyurethane pad and acid silica sol based slurries. To reduce the influence of surface work hardening, the specimens were cleaned using hydrochloric acid and distilled water prior to 
microstructure observations and nano- or Vickers indentations. There was very little change of the stress distribution in the surface region of top coat that can be neglected. As shown in Fig. 1(a), for as-received $8 \mathrm{YSZ}$ TBC coatings, there are a large amount of pores in conjunction with splat structures. After 100 thermal cycles, a noticeable sintering phenomenon occurs owing to the densification of 8YSZ and the substantial grain growth in some regions (see Fig. 1(b)). The change of microstructures may result in the change of thermo-mechanical properties of the freestanding 8YSZ coating $[18,19]$. After 250 thermal cycles, numerous macro-cracks were observed on the surface of specimens, as shown in Fig. 1(c). Further observations showed that these cracks originated from the edge or surface of TBCs and their main directions of propagation were vertical to the top coat and bond coat interface. The top coat would eventually delaminate from substrate as a whole piece due to thermal fatigue.

\subsection{X-ray diffraction}

The XRD method is based on measurement of changes in the crystal lattice spacing [12, 13], which manifest themselves as shifts in angular positions of the respective diffraction peaks. When a beam of X-ray with the wavelength of $\lambda$ is incident upon the surface of a specimen, the diffraction of X-ray occurs and meets Bragg's diffraction equation,

$$
n \lambda=2 d \sin \theta
$$

where $n$ is the order of reflection, $d$ is the crystal plane spacing, and $\theta$ is Bragg's diffraction angle. When residual stress exists in a specimen, the crystal plane spacing $d$ is different from $d_{0}$ of the specimen in an unstressed state. The strain $\varepsilon_{\psi}$ in the direction of incident angle $\psi$ can be obtained by the relative change of the diffraction crystal plane spacing, which is associated with the 
diffraction peak displacement, that is,

$$
\varepsilon_{\psi}=\frac{\Delta d}{d}=\frac{d_{\psi}-d_{0}}{d_{0}}=-\cot \theta_{0}\left(\theta_{\psi}-\theta_{0}\right)
$$

where $\theta_{0}$ is Bragg's angle at the diffraction peak in the specimen without residual stress, and $\theta_{\psi}$ is Bragg's angle with residual stress. The residual stress in top coat in the direction of $\psi$ can be given as [14]

$$
\sigma_{r}=-\frac{E}{2(1+v)} \cot \theta_{0} \frac{\pi}{180}\left(\frac{\partial 2 \theta_{\psi}}{\partial \sin ^{2} \psi}\right)
$$

Experiments showed that there is a linear relationship between $2 \theta_{\psi}$ and $\sin ^{2} \psi$. Thus, we can easily obtain the residual stress in the top coat by measuring the displacement of diffraction lines under different directions.

The residual stresses near the surface region of 8 YSZ TBC specimens were tested by XRD, including the as-received and annealed $(50,100,180$ and 250 thermal cycles) specimens. The XRD data were collected by using a D/Max 2550 diffractometer operated with filtered $\mathrm{Cu}$ radiation at 40 $\mathrm{kV}$ and $250 \mathrm{~mA}$. The penetration depth of X-ray is $10 \mu \mathrm{m}$ and the dimension of its spot is about 20 $\mu \mathrm{m}$. The XRD profile of 8YSZ TBCs with well identified peaks is shown in Fig. 2. It is seen that the 8YSZ TBCs mainly consist of tetragonal and cubic phases. The reflection used in the analysis of residual stress is the (312) plane at $\sim 95^{\circ}$, and the diffraction angle $2 \theta$ ranges from $93.5^{\circ}$ to $96.5^{\circ}$ in steps of $0.02^{\circ}$.

\subsection{Nanoindentation}

Assuming that the contact area remains constant during the initial unloading stage of nanoindentation, the apparent Young's modulus $E_{r}$ can be determined from the load-displacement or 
$P-h$ curve, which is given by [20]

$$
E_{r}=\frac{1}{2 \beta h_{c}} \sqrt{\frac{\pi}{24.5}}\left(\frac{d P}{d h}\right)
$$

where $\beta$ is a constant which depends on the geometry of an indenter $(\beta=1.034$ for a Berkovich indenter [21]), and $E_{r}$ is defined as, $1 / E_{r}=\left(1-v^{2}\right) / E+\left(1-v_{i}^{2}\right) / E_{i}$, with $E$ and $v$ the Young's modulus and Poisson's ratio of the top ceramic coat and $E_{i}$ and $v_{i}$ the Young's modulus and Poisson's ratio of the indenter, respectively. Here, the Poisson's ratio $v$ of the top coat is assumed to be 0.23 [22], and for a diamond indenter, $E_{i}=1141 \mathrm{GPa}$ and $v_{i}=0.07$ [23]. In Eq. (1), $h_{c}=h_{\max }-0.75\left(P_{\max } / S\right)$, where $P_{\max }$ is the maximum compressive load, $h_{\max }$ is the corresponding displacement, and $S=d P / d h$ is the elastic unloading stiffness. In this work, all the indentations were performed with the load control $(d P / d t=30 \mathrm{mN} / \mathrm{s})$ at $300 \mathrm{~K}$ by using a Hysitron Nanoindenter. The maximum load was set at $3 \mathrm{~N}$ and the dwelling time was $20 \mathrm{~s}$. The total of 20 perfect indentations was carried out for each specimen.

\subsection{Vickers indentation}

To verify the validity of results measured by XRD, the Vickers indentation was used to measure residual stress near the surface region of top coat. The Vickers indentation model proposed by Lawn et al. can be applied to analyze the residual stress and stress intensity factor (SIF) of 8YSZ TBCs [24-26]. For a half-penny crack configuration, the SIF can be written as [24]

$$
K=K_{p}+K_{r}=\chi \frac{P}{C^{3 / 2}}+\frac{2}{\sqrt{\pi}} \sigma_{r} C^{1 / 2}
$$

where $K_{p}$ and $K_{r}$ are SIFs produced by the indentation load $P$ and the residual stress $\sigma_{r}$, respectively, $C$ is the crack length, and $\chi=\delta(E / H)^{1 / 2}$ with $H$ being hardness and $\delta$ a 
geometric factor ( $\delta=0.015$ for a Vickers indenter). When the SIF reaches fracture toughness $K_{I C}$ of the coating, i.e., $K=K_{I C}$, Eq. (5) can be expressed as,

$$
\frac{P}{C^{3 / 2}}=\frac{K_{I C}}{\chi}-\frac{2}{\chi \sqrt{\pi}} \sigma_{r} C^{1 / 2}
$$

Obviously, there is a linear relationship between $P / C^{3 / 2}$ and $C^{1 / 2}$ [27]. The residual stress $\sigma_{r}$ and fracture toughness $K_{I C}$ can be calculated from the slope and intercept of a straight line in the rescaled plot of $P / C^{3 / 2}$ versus $C^{1 / 2}$. In experiments, the loads of 49, 98, 196, and $294 \mathrm{~N}$ were indented to the surface region of top coat, respectively. For each load, the length of indentation cracks was measured. A typical image of residual surface indentation is shown in Fig. 3, where cracks initiated near the corners of the Vickers indenter and propagated along the diagonal direction with the increase of loads.

\section{Results and discussion}

\subsection{Young's modulus}

The apparent Young's modulus obtained from nano-indentation at a given load exhibits a large scatter owing to micro- or macro-cracks and pores in APS 8YSZ TBCs. It is well known that the Weibull distribution has been usually applied to describe the scatter of mechanical properties of brittle materials [28-33]. Based on the Weibull statistics, the cumulative distribution $P$ of the measured apparent Young's modulus $E_{a p}$ can be represented as [32]

$$
P=1-\exp \left[-\left(\frac{E_{a p}}{E_{0}}\right)^{m}\right]
$$

where $E_{0}$ and $m$ are the normalized parameter and Weibull modulus, respectively. Here, the obtained experimental data are sorted in ascending order and each apparent Young's modulus is 
assigned to a probability of $P=(i-0.5) / N$, where $i$ is the $i$ th rank and $N$ is the total number of tests [33]. As shown in Fig. 4, the scattered data of apparent Young's modulus can be well fitted by the Weibull distribution for as-received and heat treated specimens. It is worth noting that the normalized parameter $E_{0}$ was used as the Young's modulus of top coat in the following study of the evolution of Young's modulus with thermal cycling in 8YSZ TBCs.

It is obvious that, as shown in Fig. 5, $E_{0}$ increases from $50 \mathrm{GPa}$ (for as-received specimens) to $93 \mathrm{GPa}$ at the thermal cycle $N=150$, and then decreases in the subsequent thermal cycles. Siebert et al. studied the change of Young's modulus in the coating of 7YSZ and found that, after an annealing time of only $2 \mathrm{~h}$, Young's modulus increased from 94 to $144 \mathrm{GPa}$ and reached $177 \mathrm{GPa}$ after $100 \mathrm{~h}$ [34]. The change of elastic modulus was also observed in the APS YSZ coating as a result of heat treatment (at $1000^{\circ} \mathrm{C}$ ), where the elastic modulus increased from 38 to $60 \mathrm{GPa}$ in spherical indentation [35]. It is obvious that our results are in good agreement with those earlier studies. The increase of $E_{0}$ is attributed to the effect of sintering that strengthens the bonding between splats and further blocks the sliding along splat boundaries, the grain growth across inter-splat boundaries, and the healing of micro-cracks [15-17]. There appear two regimes of stiffening in the increasing stage: an initially rapid rise followed by a more progressive increase, which is also in good agreement with that observed by others $[15,17]$. However, thermal fatigue stresses and interface oxidation may induce the formation and propagation of macro-cracks in the top coat $[1,2]$. In our tests, many macro-cracks occurred vertically to the top coat and bond coat interface after 160 thermal cycles, as shown in Fig. 1(c). Thus, the decrease of $E_{0}$ may be due to the breaking of bonds at splat boundaries or the formation of new macro-cracks [16]. Obviously, the Young's modulus of 8YSZ TBCs is not a constant, which varies with thermal cycles. 


\subsection{Residual stress}

In XRD measurements, the incidence angle $\psi$ is adopted as $0^{\circ}, 15^{\circ}, 30^{\circ}$, and $45^{\circ}$, respectively. The relevant diffraction peaks for as-received specimen are shown in Fig. 6. It is seen from Fig. 7 that the experimental data of each test is well fitted by a straight line in the plot of $2 \theta_{\psi}$ versus $\sin ^{2} \psi$. Then, the residual stress $\sigma_{r}$ in the top surface of 8 YSZ TBCs can be determined by the slope of the fitting line.

Let us assume that the Young's modulus of 8YSZ TBCs is a constant with the value of $50 \mathrm{GPa}$ (as-received specimens). The corresponding compressive residual stress increases from -82 to -111 MPa, as shown in Fig. 8, which agrees well with the results by Jordan et al. [12]. Hamacha et al. found that the residual stress evolution of $7 \mathrm{YSZ}$ TBCs at $1100^{\circ} \mathrm{C}$ changed from 20 to $-125 \mathrm{MPa}$ when the Young's modulus was chosen as a constant with the value of $210 \mathrm{GPa}$ [11]. For as-received APS TBCs, the residual stress measured on the surface of top coat was from -10 to $-50 \mathrm{MPa}$ by a modified layer removal method [36], and the residual stress obtained near this region was about -92 MPa by XRD [37]. However, the Young's modulus in 8YSZ TBCs was a function of thermal cycles, and the corresponding value of residual stress varied from -82 to $-190 \mathrm{MPa}$ (see Fig. 8). The difference of the calculated residual stresses is about 50 to $80 \mathrm{MPa}$, which exhibits a very obvious effect of Young's modulus on the measurement of residual stress in 8YSZ TBCs by XRD. As shown in Fig. 8, the residual stress sharply decreases after 250 thermal cycles, which may correlate with the relaxation of accumulated residual stresses induced by the formation of vertical macro-cracks (see

Fig. 1). In order to make a direct comparison to the XRD results, Vickers indentation was also used to assess the residual stresses in the surface of $\mathrm{ZrO}_{2}$, and as shown in Fig. 8, the results increased from -41 to $-201 \mathrm{MPa}$ and then dropped to $-91 \mathrm{MPa}$. Teixeira et al. found that the surface stress APS 
TBCs increased from -183 to $-240 \mathrm{MPa}$ after long time heat treatment at high temperatures [38], which is in agreement with our results. It is easy to see that the Vickers indentation results are more closely to that analyzed by XRD with Young's modulus being a variant. That is, the variation of Young's modulus as thermal cycles in $8 \mathrm{YSZ}$ top coat should be taken into account in the measurement of residual stress.

\section{Conclusions}

The reliability of coated devices is strongly related to the variation of their residual stress. In this paper, we mainly studied the influence of Young's modulus in 8YSZ coating subjected to thermal cycling on the measurement of residual stress by XRD. It is shown that there are two main stages during the evolution of Young's modulus: the increasing stage due to the effect of sintering and the relaxation stage due to the initiation and propagation of vertical macro-cracks. The scatter of the apparent Young's modulus can be well described by the Weibull distribution. Taking no account of the variation of Young's modulus in the analysis of XRD data, the difference of calculated residual stress is up to 50-80 MPa. Thus, the influence of the evolution of Young's modulus with thermal cycles on the measurement of residual stress cannot be neglected.

\section{Acknowledgments}

This work was supported by the Hunan Provincial Natural Science Foundation (No. 08JJ3003), the Fund for Young Scholars in Hunan Province (No. 08B084), the Young Teacher Fund of the Ministry of Education (No. 200805301023), and the National Natural Science Foundation of China (No. 10828205). 


\section{References}

[1] N.P. Padture, M. Gell, E.H. Jordan, Science 296 (2002) 280-284.

[2] A.G. Evans, D.R. Mumm, J.W. Hutchinson, G.H. Meier, F.S. Pettit, Prog. Mater Sci. 46 (2001) $505-553$.

[3] A.G. Evans, M.Y. He, J.W. Hutchinson, Prog. Mater Sci. 46 (2001) 249-271.

[4] S.R. Choi, J.W. Hutchinson, A.G. Evans, Mech. Mater. 31 (1999) 431-447.

[5] J.W. Hutchinson, A.G. Evans, Surf. Coat. Technol. 149 (2002) 179-184.

[6] J.W. Hutchinsona, M.Y. He, A.G. Evans, J. Mech. Phys. Solids 48 (2000) 709-734.

[7] W.G. Mao, C.Y. Dai, Y.C. Zhou, Q.X. Liu, Surf. Coat. Technol. 201 (2007) 6217-6227.

[8] A.N. Khan, J. Lu, H. Liao, Surf. Coat. Technol. 168 (2003) 291-299.

[9] C.H. Hsueh, J. Appl. Phys. 91 (2002) 9652-9656.

[10] P. Scardi, M. Leoni, L. Bertamini, M. Marchese, Surf. Coat. Technol. 86-87 (1996) 109-115.

[11] R. Hamacha, B. Dionnet, A. Grimaud, F. Nardou, Surf. Coat. Technol. 80 (1996) 295-303.

[12] D.W. Jordan, K.T. Faber, Thin Solid Films 235 (1993) 137-141.

[13] J. Matejicek, S. Sampath, J. Dubsky, J. Therm. Spray Technol. 7 (1998) 489-496 .

[14] X. Fan, X-ray Diffraction Mechanism (in Chinese), Mechanism Industry Publisher, Beijing, China, 1981.

[15] S.Q. Guo, Y. Kagawa, Scripta Mater. 50 (2004) 1401-1406.

[16] F. Tang, J. M. Schoenung, Scripta Mater. 54 (2006) 1587-1592.

[17] J.A. Thompson, T.W. Clyne, Acta Mater. 49 (2001) 1565-1575.

[18] D.M. Zhu, R.A. Miller, Surf. Coat. Technol. 108 (1998) 114-120.

[19] S. Paul, A. Cipitria, S.A. Tsipas, T.W. Clyne, Surf. Coat. Technol. 203 (2009) 1069-1074. 
[20] W.C. Oliver, G.M. Pharr, J. Mater. Res. 7 (1992) 1564-1583.

[21] R.B. King, Int. J. Solids Stru. 23 (1987) 1657-1664.

[22] K.A. Khor, Y.W. Gu, Mater. Sci. Eng. A 277 (2000) 64-76.

[23] G. Simmons, H. Wang, A Handbook, MIT Press, Cambridge, MA, 1971.

[24] D.B. Marshall, B.R. Lawn, J. Am. Ceram. Soc. 60 (1977) 86-87.

[25] G.R. Anstis, P. Chantikul, B.R. Lawn, D.B. Marshall, J. Am. Ceram. Soc. 64 (1981) 533-538.

[26] P. Chantikul, G.R. Anstis, B.R. Lawn, D.B. Marshall, J. Am. Ceram. Soc. 64 (1981) 539-543.

[27] J. Lesage, D. Chicot, C. Godoy, Thin Solid Films 415 (2002) 143-150.

[28] T.Y. Zhang, L.Q. Chen, R. Fu, Acta Mater. 47 (1999) 3869-3878.

[29] S.Q. Guo, Y. Kagawa, Surf. Coat. Technol. 182 (2004) 92-100.

[30] S.Q. Guo, Y. Kagawa, Ceram. Int. 32 (2006) 263-270.

[31] J.H. Gong, Ceram. Int. 28 (2002) 767-772.

[32] W. Weibull, J. Appl. Mech. 18 (1951) 239-297.

[33] C. Lu, R. Danzer, F.D. Fischer, Phys. Rev. E 65 (2002) 067102.

[34] B. Siebert, C. Funke, R. Vaben, D. Stöver, J. Mater. Process. Technol. 92 (1999) 217-223.

[35] M. Eskner, R. Sandström, Surf. Coat. Technol. 177 (2004) 165-171.

[36] P. Bengtsson, C. Persson, Surf. Coat. Technol. 92 (1997) 78-86.

[37] A. Portinha, V. Teixeira, J. Carneiro, et al., Surf. Coat. Technol. 188-189 (2004) 120-128.

[38] V. Teixeira, M. Andritschky, W. Fischer, H.P. Buchkremer, D. Stöver, Surf. Coat. Technol. $120-121(1999)$ 103-111 


\section{Figure captions}

Fig. 1 Optical micrographs of the polished surfaces of (a) as-received, (b) heat-treated (100 cycles), and (c) heat-treated (250 cycles) 8YSZ TBC specimens.

Fig. 2 The XRD pattern of the as-received 8YSZ TBC specimen.

Fig. 3 The optical micrograph of a residual indentation (black impression) at $196 \mathrm{~N}$ on an annealed specimen (100 cycles).

Fig. 4 The Weibull plots of apparent Young's modulus under different thermal cycles.

Fig. 5 The Young's modulus of the surface top coat as a function of thermal cycling at $1403 \mathrm{~K}$, where the testing error ranges from 1 to $3 \mathrm{GPa}$.

Fig. 6 The XRD pattern on the (312) plane of as-received 8YSZ TBCs with different incident angles.

Fig. 7 A typical plot of $2 \theta$ versus $\sin ^{2} \psi$ for the as-received 8YSZ TBC specimen.

Fig. 8 Comparison of the residual stress in the top coat of $8 \mathrm{YSZ}$ as a function of thermal cycling at $1403 \mathrm{~K}$, where the error bars refer to the standard deviation of five tests. 
able 1. Plasma spraying parameters for NiCrAlY and 8YSZ coatings, where the NiCrAlY layer was sprayed on substrate by using low vacuum plasma and then the 8YSZ layer was spayed on the surface of bond coat by using air plasma.

\begin{tabular}{|c|c|c|c|c|c|c|}
\hline Powder & $\begin{array}{c}\text { Working gas Ar/N } \\
(\text { liter/min })\end{array}$ & $\begin{array}{c}\text { Current } \\
(\mathrm{A})\end{array}$ & $\begin{array}{c}\text { Voltage } \\
(\mathrm{V})\end{array}$ & $\begin{array}{c}\text { Feed rate } \\
(\mathrm{g} / \mathrm{min})\end{array}$ & $\begin{array}{c}\text { Stand-off distance } \\
(\mathrm{mm})\end{array}$ & $\begin{array}{c}\text { Carrier gas Ar } \\
(\text { liter/min })\end{array}$ \\
\hline NiCrAlY & $30 / 12$ & 450 & $40-55$ & 10 & $150-200$ & 5.0 \\
\hline 8YSZ & $30 / 12$ & 450 & $40-55$ & 5 & $100-120$ & 4.5 \\
\hline
\end{tabular}



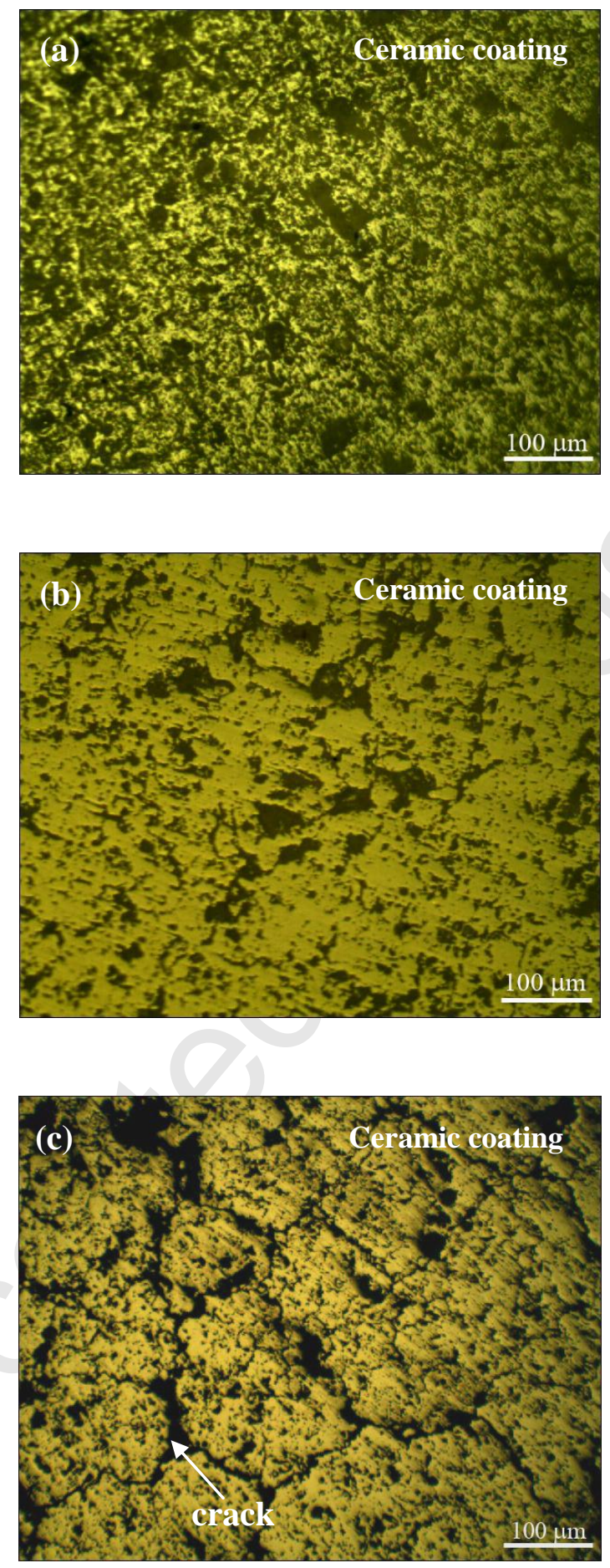

Fig. 1 


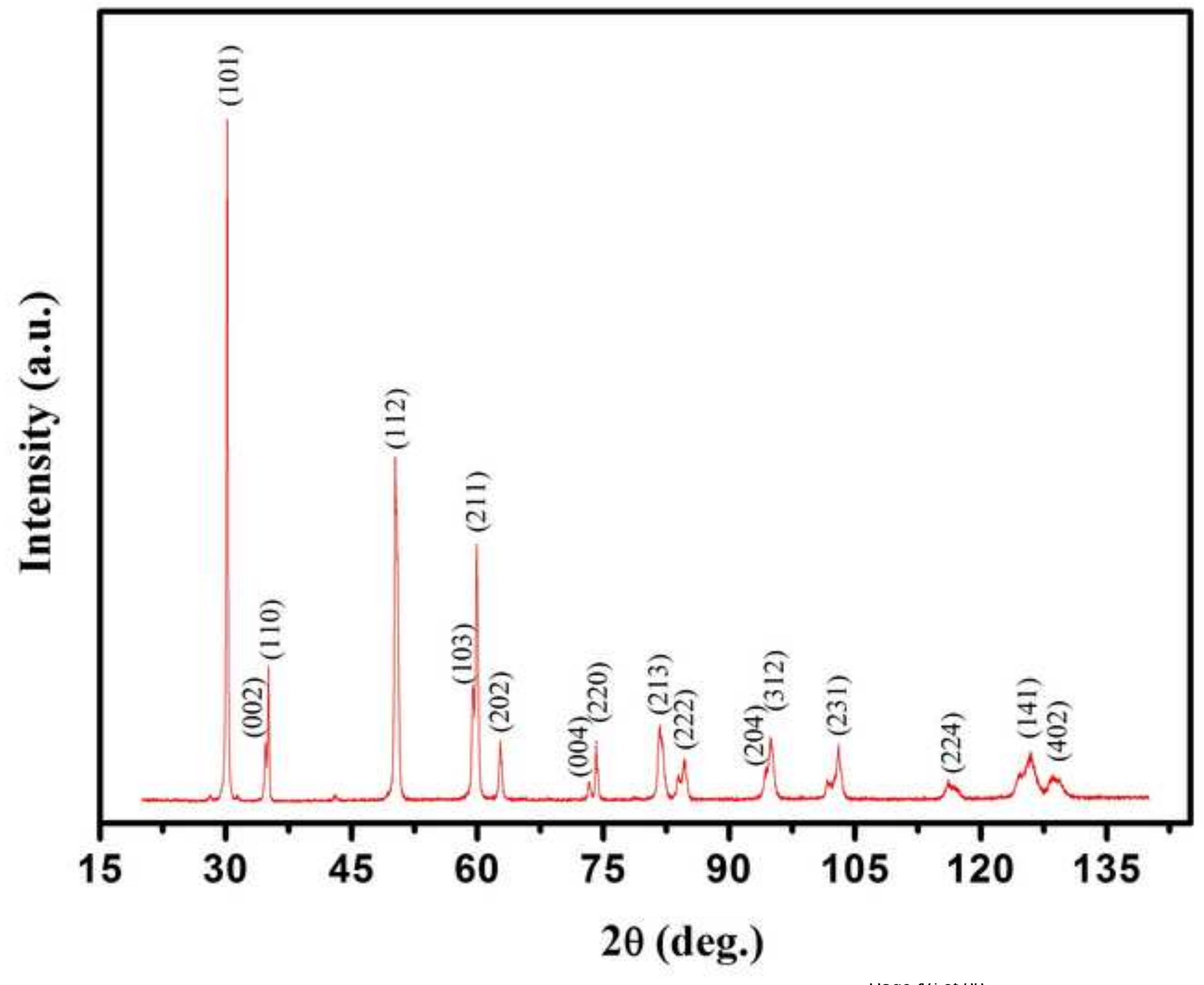

rage 16 or $2<$

rage 16012 


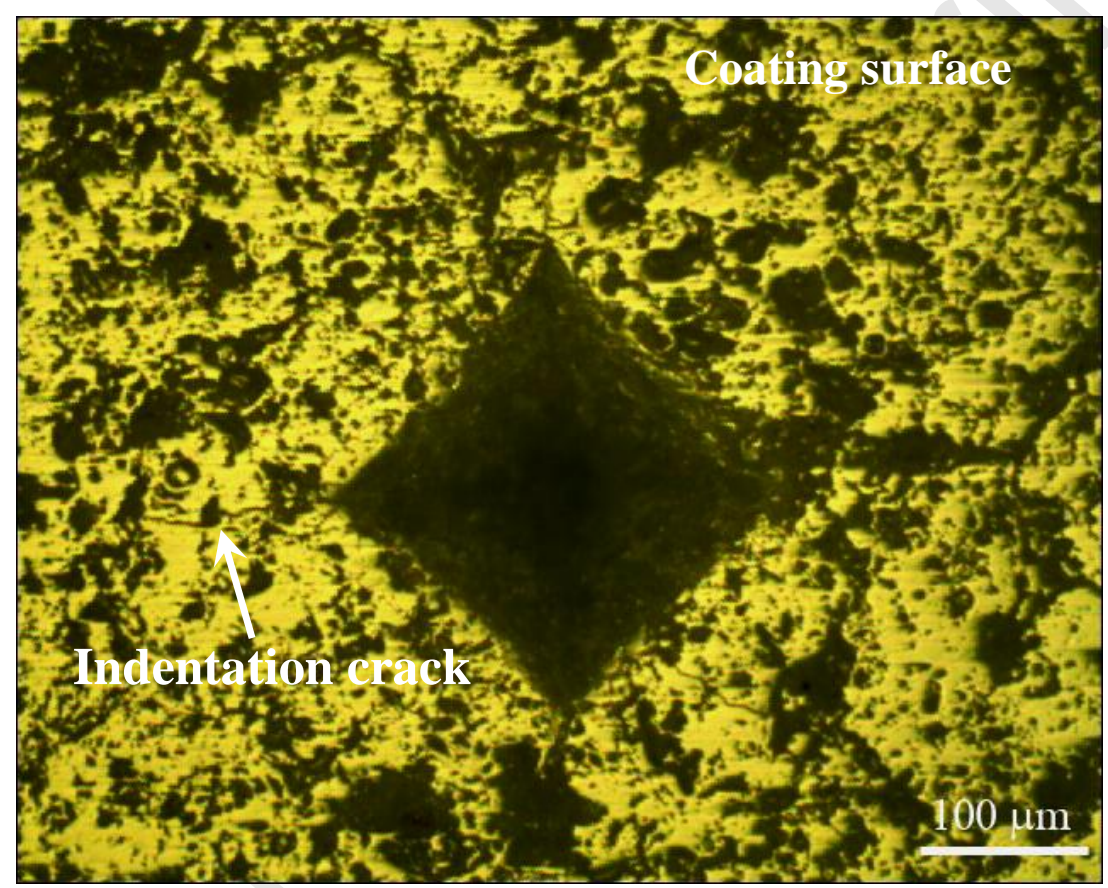

Fig. 3 


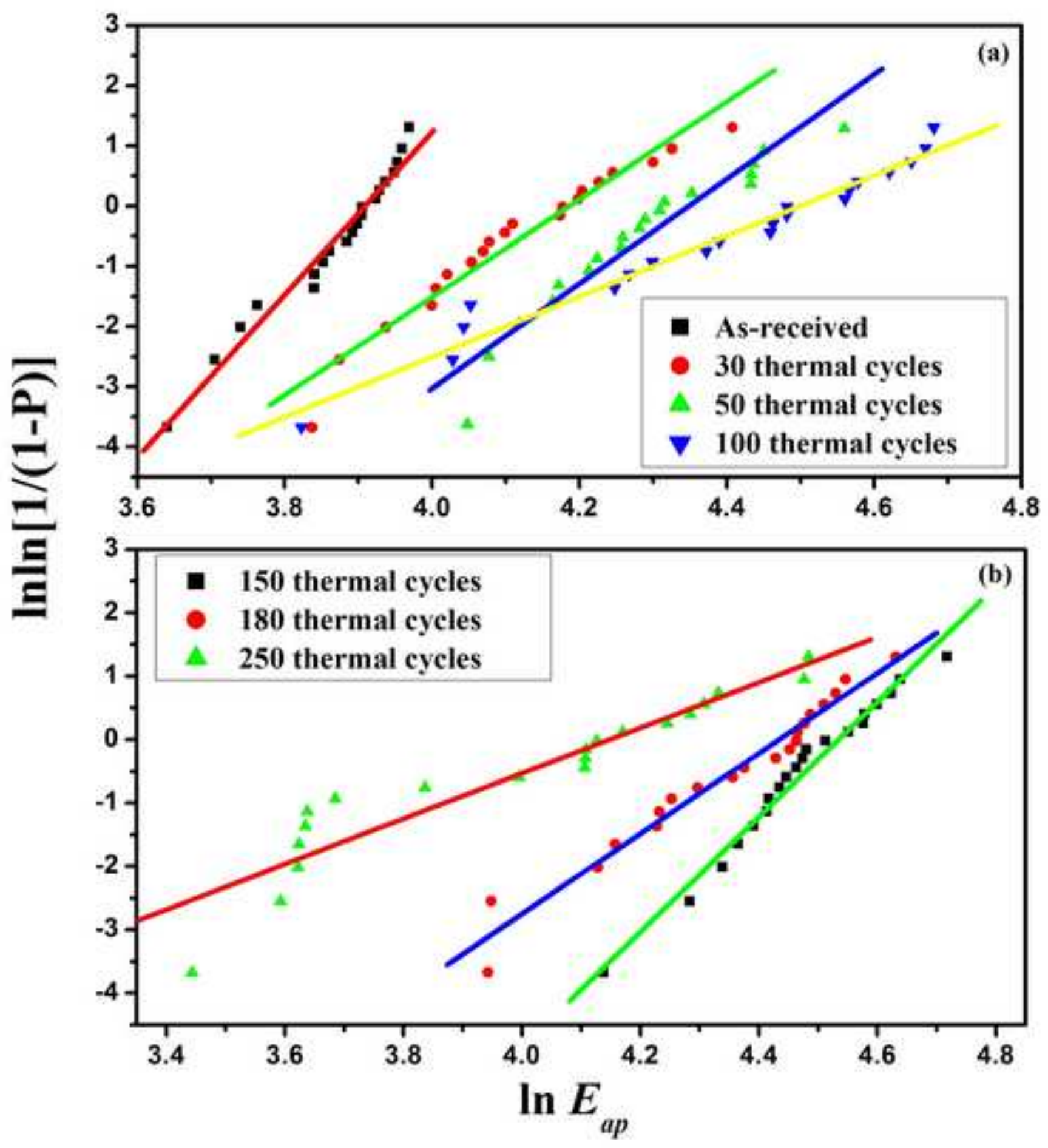

Page 18 of 22 


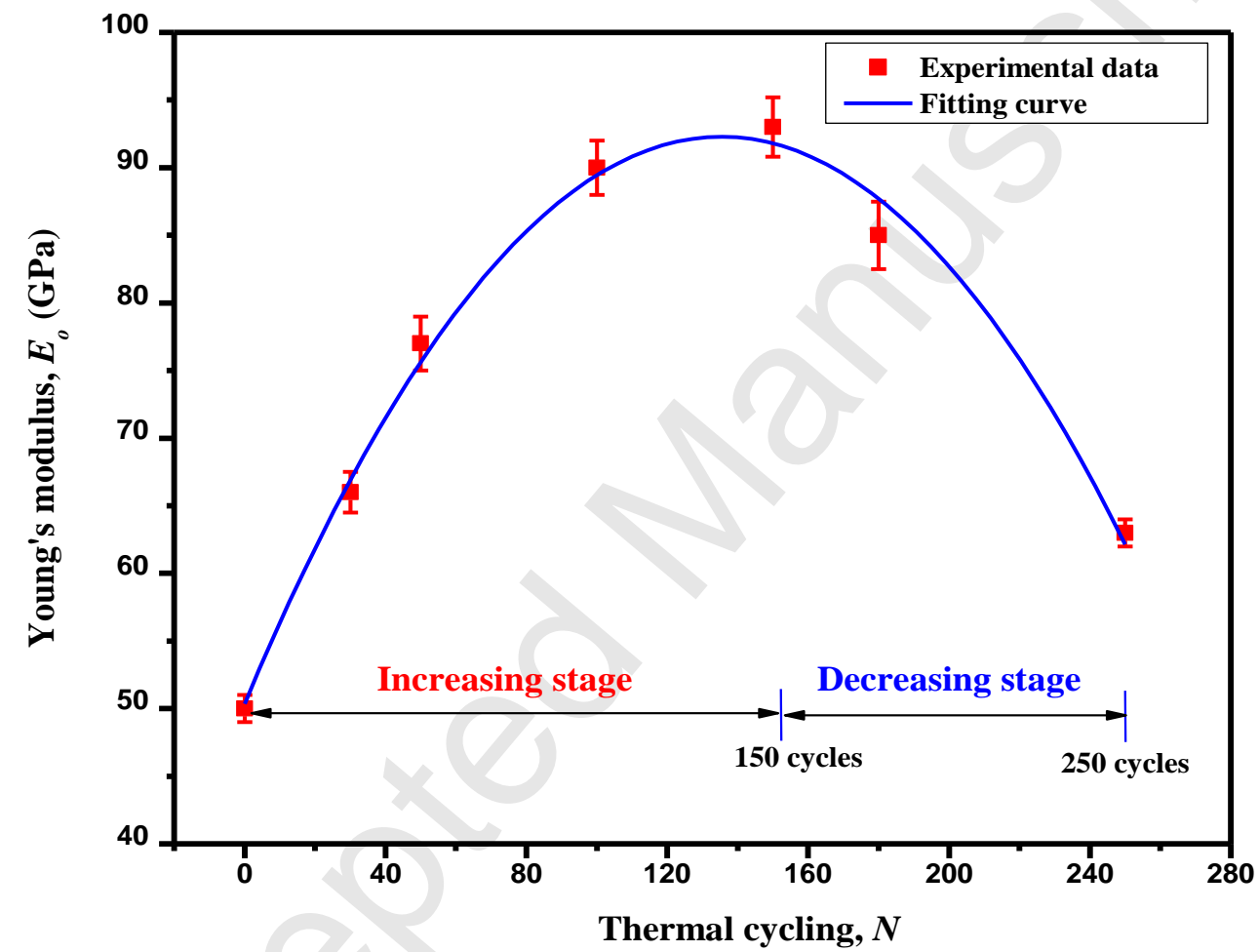

Fig. 5 


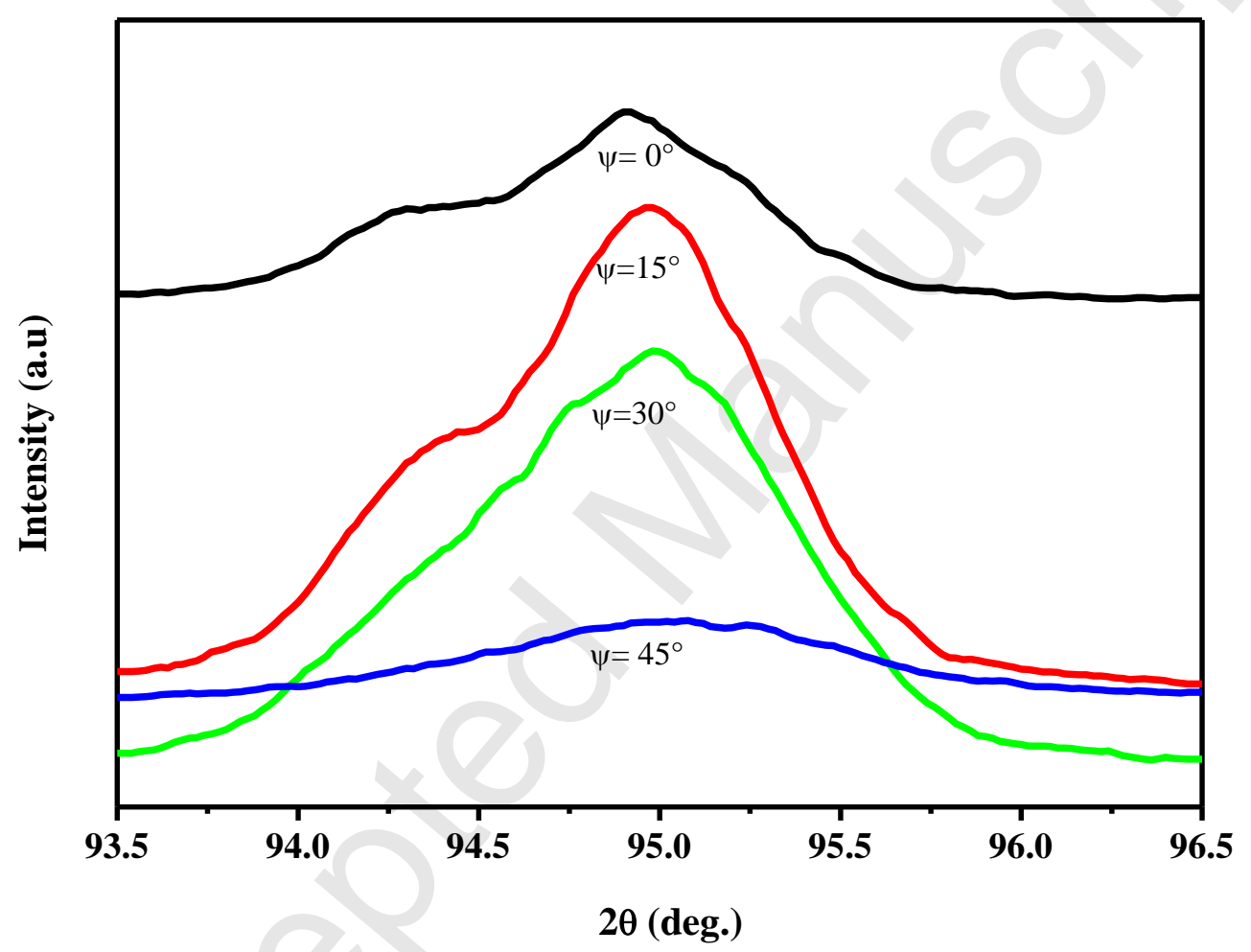

Fig. 6 


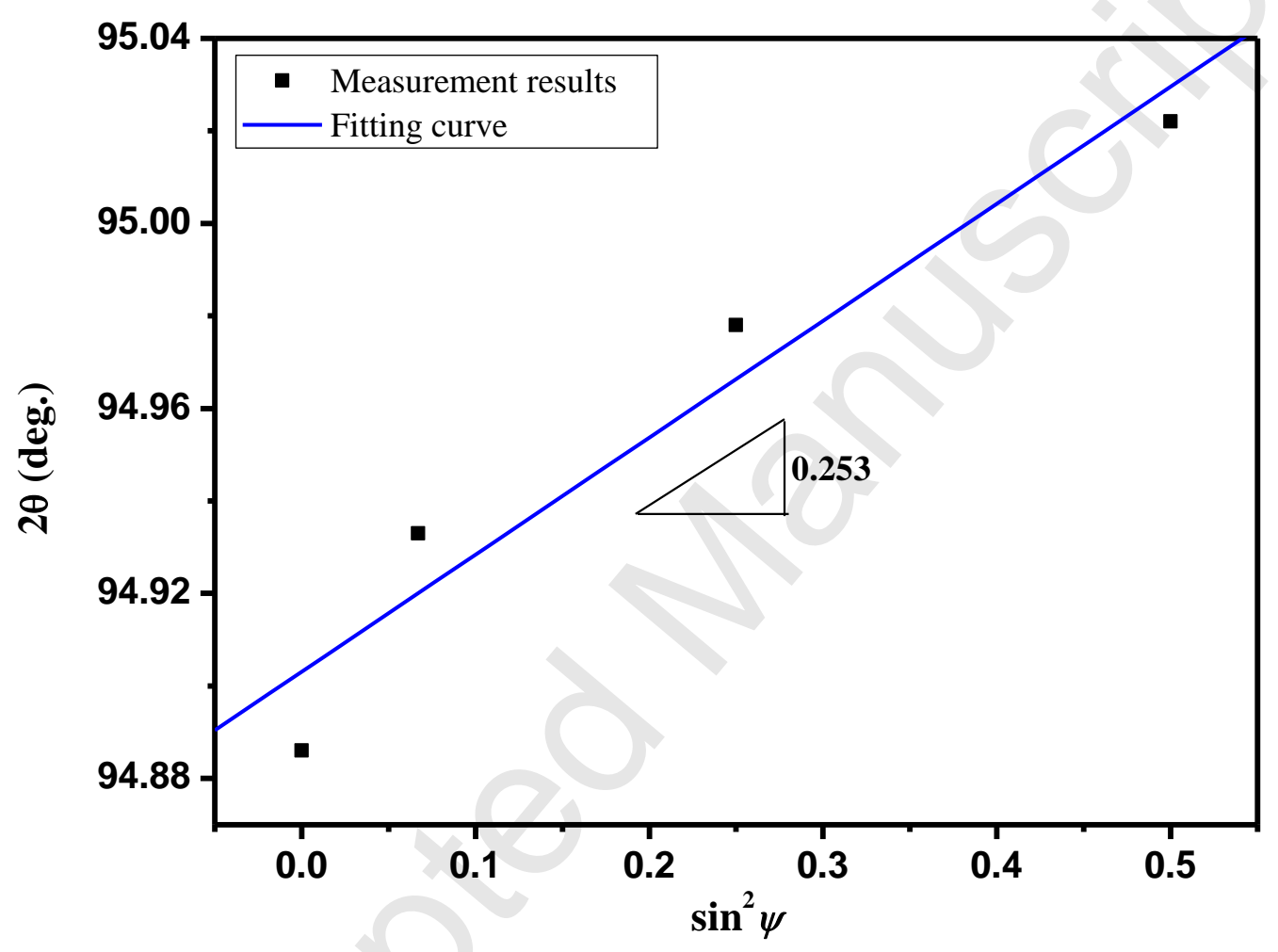

Fig. 7 


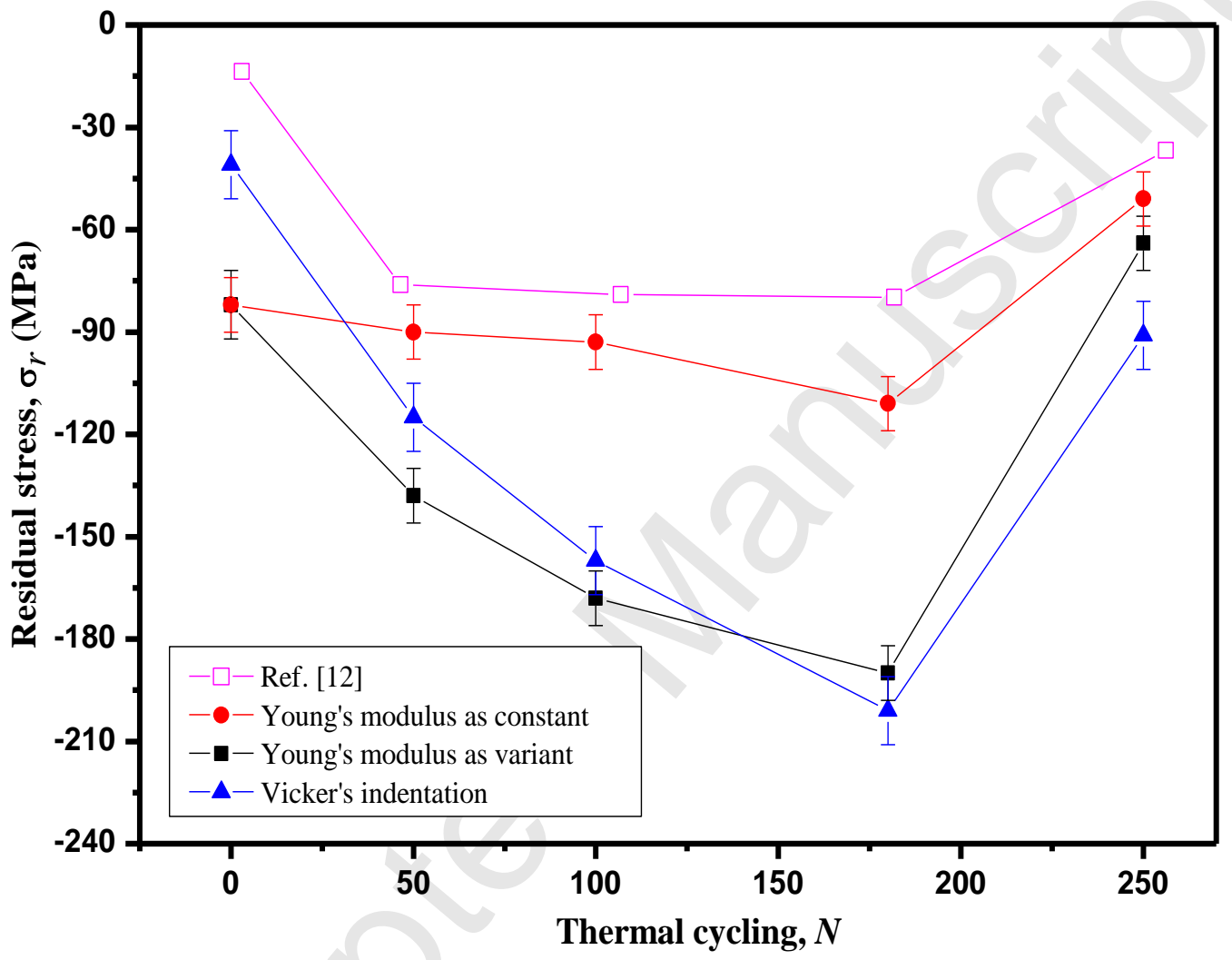

Fig. 8 